\title{
Quantificação de metabólitos secundários e avaliação da atividade antimicrobiana e antioxidante de algumas plantas selecionadas do Cerrado de Mato Grosso
}

\author{
LIMA NETO, G.A.'; KAFFASHI, S.'; LUIZ, W.T.'; FERREIRA, W.R.'; DIAS DA SILVA, Y.S.A.'; PAZIN, G.V.'; \\ VIOLANTE, I.M.P. ${ }^{*}$ \\ Universidade de Cuiabá, Faculdade de Farmácia, Campus Beira Rio, Av: Manoel José de Arruda, 3100, Bairro \\ Jardim Europa, CEP: 78065-900, Cuiabá, MT, Brasil. *Autor para correspondência:impv@terra.com.br
}

\begin{abstract}
RESUMO: Extratos etanólicos de Luehea paniculata, Anadenanthera colubrina, Cariniana rubra, Hancornia speciosa, Qualea grandiflora, Kielmeyera coriaceae e Palicourea rigida, coletadas no Cerrado de Mato Grosso foram submetidos à análise fitoquímica preliminar para identificação das principais classes de metabolitos secundários e à quantificação do teor de compostos fenólicos totais, flavonoides e cumarinas. O estudo também descreve a atividade antimicrobiana, antioxidante e a toxicidade preliminar frente a larvas de Artemia salina. Os extratos de $C$. rubra e $Q$. grandiflora foram os mais ativos contra as cepas fúngicas de $C$. neoformans (CIM 3,91 $\mu \mathrm{g} / \mathrm{mL}$ ), C. krusei (CIM 15,63 $\mu \mathrm{g} / \mathrm{mL}$ ), C. parapsilosis (CIM 31,25 $\mu \mathrm{g} / \mathrm{mL}$ ) e C. albicans (CIM 62,5 $\mu \mathrm{g} / \mathrm{mL}$ ), ambos com os mesmos resultados para estes microrganismos. Em relação às cepas bacterianas a mais sensível foi $S$. aureus com CIM de $250 \mu \mathrm{g} / \mathrm{mL}$ para todos os extratos testados. Luhea paniculata e $Q$. grandiflora foram as espécies vegetais mais ativas contra E. coli (CIM 500 e $250 \mu \mathrm{g} / \mathrm{mL}$, respectivamente) e E. faecalis (CIM 250 e $500 \mu \mathrm{g} /$ $\mathrm{mL}$, respectivamente). No teste do DPPH, merece destaque as espécies $K$. coriaceae (Ca) $\left(\mathrm{IC}_{50}=0,72 \pm 0,51 \mu \mathrm{g} / \mathrm{mL}\right), K$. coriaceae $(\mathrm{Fo})\left(\mathrm{IC}_{50}=1,34 \pm 0,53 \mu \mathrm{g} / \mathrm{mL}\right), H$. speciosa $(\mathrm{Fo})\left(\mathrm{IC}_{50}\right.$ $=1,03 \pm 0,52 \mu \mathrm{g} / \mathrm{mL}), Q$. grandiflora $(F o)\left(I C_{50}=1,31 \pm 0,19 \mu \mathrm{g} / \mathrm{mL}\right)$ e $P$. rigida $(\mathrm{Fo})\left(\mathrm{IC}_{50}=1,39\right.$ $\pm 0,53 \mu \mathrm{g} / \mathrm{mL}$ ). Com exceção de $L$. paniculata $(F o)$, que apresentou $I C_{50}$ de $14,40 \pm 0,34 \mu \mathrm{g} / \mathrm{mL}$ e teor de flavonoides de $295,5 \mathrm{mg} / \mathrm{g}$, todas as espécies que tiverem significativa atividade no teste do DPPH, também apresentaram teor de flavonoides semelhante ao padrão, ou seja, $H$. speciosa (Fo) (280,5 mg/g), Q. grandiflora (Fo) $(260,5 \mathrm{mg} / \mathrm{g})$, K. coriaceae (Ca) $(250,5 \mathrm{mg} / \mathrm{g}), \mathrm{K}$. coriaceae (Fo) $(235,5 \mathrm{mg} / \mathrm{g})$. Quanto à determinação de fenóis totais e cumarinas os resultados foram inferiores quando comparados aos padrões.
\end{abstract}

Palavras-chave: Cerrado, antimicrobiana, fenóis totais, flavonoides, DPPH.

\begin{abstract}
Quantification of secondary metabolites and antimicrobial and antioxidant activities of some medicinal plants from the Cerrado of the Mato Grosso. Ethanol extracts of Luehea paniculata, Anadenanthera colubrina, Cariniana rubra, Hancornia speciosa, Qualea grandiflora, Kielmeyera coriaceae and Palicourea rigida, collected in the Cerrado of Mato Grosso went through preliminary phytochemical analysis in order to identify major classes of secondary metabolites and also to quantify the total content of phenolics, flavonoids and coumarins. The study also describes the antimicrobial and antioxidant activity and the toxicity of the larva of Artemia salina. The C. rubra extracts and the Q. grandiflora were the most active against fungal strains of C. neoformans (MIC $3.91 \mu \mathrm{g} / \mathrm{ml}$ ), C. krusei (MIC $15.63 \mu \mathrm{g} / \mathrm{ml}$ ), C. parapsilosis (31.25 $\mathrm{MIC} \mu \mathrm{g} / \mathrm{ml}$ ) and C. albicans (MIC $62.5 \mu \mathrm{g} / \mathrm{ml}$ ), both with the same results for these organisms. Regarding the bacterial strains, the most sensitive one was the $S$. aureus with $250 \mu \mathrm{g} / \mathrm{ml} \mathrm{MIC}$ for all the tested extracts. The Luhea paniculata and the Q. grandiflora were the most active against E. coli species (MIC 500 and $250 \mu \mathrm{g} / \mathrm{ml}$, respectively) and E. faecalis (MIC 250 and $500 \mu \mathrm{g} / \mathrm{ml}$, respectively). In the test of DPPH, $K$. coriaceae $(\mathrm{Ca})\left(\mathrm{IC}_{50}=0.72 \pm 0.51 \mu \mathrm{g} / \mathrm{mL}\right), K$. coriaceae (Fo) $\left(\mathrm{IC}_{50}=1.34 \pm 0.53 \mu \mathrm{g} / \mathrm{mL}\right), H$. speciosa (Fo) $\left(\mathrm{IC}_{50}=1.03 \pm 0.52 \mu \mathrm{g} / \mathrm{mL}\right)$, Q. grandiflora (Fo) $\left(\mathrm{IC}_{50}=1.31 \pm 0.19 \mu \mathrm{g} / \mathrm{ml}\right)$ and $P$. rigida $(\mathrm{Fo})(1.39 \pm 0,53 \mu \mathrm{g} / \mathrm{ml})$ stood out. With the exception of the $L$. paniculata (Fo), which showed an IC50 of $14.40 \pm 0.34 \mu \mathrm{g} / \mathrm{ml}$ and a flavonoid content of $295.5 \mathrm{mg} / \mathrm{g}$, all species that had significant activity in the DPPH test, also showed flavonoid
\end{abstract}

Recebido para publicação em 05/12/2014

Aceito para publicação em 02/06/2015

10.1590/1983-084X/14_161

Rev. Bras. PI. Med., Campinas, v.17, n.4, supl. III, p.1069-1077, 2015. 
content similar to the standard one, or $\mathrm{H}$. speciosa $(\mathrm{Fo})(280.5 \mathrm{mg} / \mathrm{g})$ Q. grandiflora (Fo) $(260.5$ $\mathrm{mg} / \mathrm{g})$, K. coriaceae (Ca) $(250.5 \mathrm{mg} / \mathrm{g})$, K. coriaceae (Fo) $(235.5 \mathrm{mg} / \mathrm{g})$.

Keywords: Cerrado, antimicrobial, total phenols, flavonoids, DPPH.

\section{INTRODUÇÃO}

O Cerrado possui uma vegetação heterogênea cuja biodiversidade taxonômica é composta por mais de 7000 espécies nativas de plantas vasculares (Hiruma-Lima et al., 2006; Napolitano et al., 2005). Devido a essa notável diversificação florística, tem-se observado um crescente interesse na investigação de plantas medicinais do Cerrado, como fonte de compostos bioativos (Guarin Neto \& Morais, 2003). No entanto, encontra-se há alguns anos na lista "hot spots", onde configuram os 25 biomas mais ameaçados de extinção (Sawyer, et al., 2008). Estes dados são preocupantes e por estas razões torna-se necessário ampliar o estudo interdisciplinar deste bioma objetivando seu manejo sustentável.

A utilização de plantas medicinais é um recurso terapêutico de grande aceitação pela população e vem crescendo junto à comunidade médica, desde que sejam utilizadas plantas, cujas atividades biológicas tenham sido investigadas cientificamente, comprovando sua eficácia e segurança (Kinghorn, 2001). A importância das plantas medicinais deve-se também por sua contribuição como fonte natural de fármacos e por proporcionar grandes chances de obter-se uma molécula protótipo devido à diversidade de constituintes presentes nestas (Cechinel Filho \& Yunes, 1998).

O Estado de Mato Grosso possui diversas comunidades tradicionais, principalmente em áreas de Cerrado e de Pantanal, que utilizam plantas medicinais mediante o conhecimento popular transmitido dos seus ancestrais (Macedo \& Ferreira, 2004).

Desde o início dos anos 80 o número de antimicrobianos em fase de desenvolvimento diminuiu consideravelmente. Em contrapartida, a resistência dos microrganismos aos mesmos tem crescido de forma imensurável, porque eles estão cada vez mais desenvolvendo uma série de mecanismos de resistência, repassados de geração a geração (Antunes et al., 2006). A resistência bacteriana e fúngica é um sério problema do ponto de vista clínico e de saúde pública, influenciando drasticamente no período de hospitalização, nos índices de morbidade e mortalidade, repercutindo de maneira significativa nos custos, especialmente considerando o prolongamento da internação, o consumo de antibióticos, os gastos com isolamento e os exames laboratoriais (Andrade et al., 2006).
O efeito cumulativo dos radicais livres no organismo implica em doenças como câncer, ateroscleroses, isquemia cerebral e envelhecimento. Antioxidantes que sequestram os radicais livres, previnem e apresenta alto potencial terapêutico contra as doenças citadas acima, o que tem gerado uma busca de novos potenciais antioxidantes derivados de plantas utilizadas na medicina popular (Antas \& Silva et al., 2006).

A metodologia mais comum para se determinar a atividade antioxidante de modo prático, rápido e sensível são as que envolvem um radical cromóforo, simulando as espécies reativas de oxigênio (EROs), sendo o radical livre DPPH (2,2-difenil-1-picril-hidrazila) um dos mais utilizados (Arnao et al. 2000).

Os metabólitos secundários possuem atividades biológicas importantes, muitos são de grande valor comercial. Do ponto de vista farmacêutico, o maior interesse está no número elevado de substâncias farmacologicamente importantes. Várias técnicas podem ser empregadas para a detecção e a quantificação de metabolitos secundários em amostras de espécies vegetais, e os métodos espectrofotométricos são os mais práticos, reprodutíveis e baratos do que outras metodologias, permitindo a análise de compostos na região do ultravioleta ou visível (Sobrinho et al., 2011). Compostos fenólicos que possuem um ou mais grupos hidroxilas ligados a um anel aromático destacam-se de outras classes de metabólitos secundários porque são amplamente distribuídos e por possuírem várias funções ecológicas e inúmeras atividades farmacológicas, cientificamente comprovadas, sendo bem representadas por taninos, flavonoides e cumarinas (Amorim et al., 2008).

O método de análise com Artemia salina é proposto como um simples bioensaio para pesquisa preliminar de atividade de produtos naturais. Por esse método, é possível determinar a concentração letal $50 \%\left(\mathrm{DL}_{50}\right)$ de componentes ativos e extratos em meio salino, o que é manifestado pela toxicidade de componentes ativos, frações ou extratos de produtos naturais frente ao organismo marinho $A$. salina (Meyer, 1982; McLaughlin, 1998).

Neste estudo, buscou-se estimar qualitativamente o perfil químico das espécies vegetais em estudo e determinar o teor total de fenóis totais, flavonoides, e cumarinas, bem como

Rev. Bras. PI. Med., Campinas, v.17, n.4, supl. III, p.1069-1077, 2015. 
avaliar a atividade antimicrobiana, sequestradora de radicais livres e a toxicidade frente à Artemia salina de extratos brutos obtidos de plantas medicinais oriundas do Cerrado de Mato Grosso.

\section{MATERIAL E MÉTODO \\ Obtenção dos extratos}

As plantas foram coletadas na região do Rio Manso, município da Chapada dos Guimarães, Mato Grosso, tendo como coordenadas: altitude $15^{\circ}$ $15^{\prime} 16^{\prime \prime}$ 'S e longitude $55^{\circ} 43^{\prime} 34^{\prime \prime} \mathrm{O}$. Os extratos foram obtidos a partir de partes específicas (Tabela 1) das espécies vegetais Luehea paniculata Mart. \& Zucc, Anadenanthera colubrina (Vell.) Brenan, Cariniana rubra Gardiner ex Miers, Hancornia speciosa Gomez, Qualea grandiflora Mart. EC, Kielmeyera coriaceae (Spreng.) Mart. e Palicourea rigida H.B.K., limpas por meio de água corrente, com posterior secagem em estufa de ar circulante $a 40^{\circ} \mathrm{C}$, durante uma semana para as folhas e duas semanas para a entrecascas. Posteriormente, o material foi triturado e pulverizado em moinho de facas elétrico (Tecnal, Modelo 680). O material foi macerado durante sete dias em álcool etílico (90\%) à temperatura ambiente. O filtrado foi submetido à evaporação lenta, sob pressão reduzida, à temperatura de $40{ }^{\circ} \mathrm{C}$, em aparelho evaporador rotativo (Fisaton, Modelo 802) até a concentração dos extratos.

\section{Análise fitoquímica preliminar}

O extrato foi submetido à triagem fitoquímica preliminar para detecção das principais classes de metabólitos secundários através de reações químicas que resultam no desenvolvimento de coloração e/ou precipitado, característico para cada classe de substâncias (Moreira, 1979; Matos, 1997.
Simões et al., 2004). (Tabela 2).

\section{Determinação do teor de metabólitos secundários}

Para determinação do teor de compostos fenólicos (TCF) foi utilizado o método espectrofotométrico de Folin-Ciocalteu. Os resultados foram expressos em $1 \mathrm{mg}$ de ácido tânico por grama da amostra (mg EAT/g). A equação de calibração do ácido tânico foi y $=0,005 x+$ $0,0012\left(R^{2}=0,9946\right)$. A determinação do teor total de flavonoides (TTF) foi estimada por um método colorimétrico baseado na formação de um complexo alumínio-flavonoide. Os resultados foram expressos em $1 \mathrm{mg}$ de rutina por grama da amostra $(\mathrm{mg} \mathrm{ER} / \mathrm{g})$. A equação de calibração da rutina foi $y=0,002 x+$ $0,999\left(R^{2}=0.999\right)$. A determinação de cumarinas dos extratos foi estabelecida pela equação de calibração $y=0,007 x+0,0019\left(R^{2}=0,9997\right)$, e o teor de cumarinas foi expresso em miligramas de cumarina por grama de extrato (mg EC/g). As amostras foram deixadas em repouso, no escuro, durante 30 minutos e a absorbância foi avaliada nos comprimentos de onda a 760, 420 e $320 \mathrm{~nm}$, para a determinação de fenóis totais e taninos, flavonoides e cumarinas, respectivamente. Como controle negativo utilizou-se todos os reagentes menos as amostra.

\section{Ensaio da atividade sequestradora de radicais livres pelo método do DPPH}

A avaliação quantitativa da capacidade sequestradora de radicais livres das amostras analisadas foi determinada através do método de doseamento fotocolorimétrico do radical 2,2-difenil-1-picril-hidrazila (DPPH) (Aldrich $\mathrm{Co}^{\circledR}$ ), em processo guiado pela redução e descoloração

TABELA 1. Identificação das espécies de uso na medicina popular, nome vernacular, parte da planta utilizada e respectivos números de registro no Herbário Central da Universidade Federal de Mato Grosso - UFMT.

\begin{tabular}{lllll}
\hline Nome Científico & Família & Nome vernacular & Parte da planta usada & n $^{\circ}$ exsicata \\
\hline Luehea paniculata Mart. \& Zucc & Tiliaceae & Açoita cavalo & Ec e Fo & 23772 \\
Anadenanthera colubrina (Vell.) Brenan & Mimosaceae & Angico & Ec & 23749 \\
Cariniana rubra Gardiner ex Miers & Lecythidaceae & Jequitibá & Ec & 39419 \\
Hancornia speciosa Gomez & Apocinaceae & Mangaba & Ec e Fo & 23783 \\
Qualea grandiflora Mart. & Vochysiaceae & Pau terra & Ec e Fo & 23773 \\
Kielmeyera coriaceae (Spreng.) Mart. & Clusiaceae & Pau santo & Ca e Fo & 23751 \\
Palicourea rigida H.B.K & Rubiaceae & Douradão & Fo & 23755 \\
\hline
\end{tabular}

Ec: Entrecasca; Fo; Folhas; Ca: Caule.

Rev. Bras. PI. Med., Campinas, v.17, n.4, supl. III, p.1069-1077, 2015. 
deste em solução alcoólica na presença de agentes antioxidantes. Neste teste, o radical estável DPPH absorve entre $515-528 \mathrm{~nm}$ (cor violeta), contudo, ao ser reduzido por um agente antioxidante (doador de hidrogênio) ou uma espécie radicalar, ocorre a formação da difenil-picril-hidrazina, de coloração amarela, com consequente desaparecimento da absorção, sendo a mesma monitorada pelo decréscimo da absorbância (Silva et al., 2005).

A solução de DPPH foi preparada em etanol em uma concentração de $200 \mu \mathrm{g} / \mathrm{mL}$. Os extratos brutos e o padrão [controle positivo Ácido cafêico (Fukla®)] foram inicialmente diluídos em etanol na proporção de $1000 \mu \mathrm{g} / \mathrm{mL}$ (1:1). Em seguida, foi realizada uma segunda diluição, para que se obtivesse uma concentração de $400 \mu \mathrm{g} / \mathrm{mL}$. Desta forma, as concentrações finais na placa de microtitulação (96 orifícios), foram na faixa de 200 a $3,125 \mu \mathrm{g} / \mathrm{mL}$ para os extratos. O controle positivo e branco (etanol) foi submetido às mesmas condições de preparação e análise utilizadas para todas as amostras. O teste foi realizado em triplicata (nas colunas 1,2 e 3 ) e realizado segundo a descrição abaixo:

Foram adicionados $200 \mu \mathrm{L}$ de etanol (EtOH) na placa de microtitulação e realizou-se a leitura em espectrofotômetro de microplaca (Thermo Plate-TPReader), descartou- se o etanol e deixou a placa secar. Em seguida, foram adicionados $100 \mu \mathrm{L}$ da amostra nos orifícios das linhas Ae B (colunas 1, $2 \mathrm{e}$ 3); $100 \mu \mathrm{L}$ de etanol nos orifícios das linhas $B$ até $\mathrm{H}$. Procedeu-se então uma diluição seriada dos orifícios das linhas B ao G. Após, adicionou-se $100 \mu \mathrm{L}$ da solução de DPPH nos orifícios das linhas $A$ até $H$.

Após uma reação de 30 min à temperatura ambiente e ausência de luz, a absorbância (ABS) foi determinada a $517 \mathrm{~nm}$. Assim, a partir dos resultados obtidos, determinou-se a porcentagem de atividade antioxidante ou sequestradora de radicais livres e/ ou a porcentagem de DPPH remanescente no meio reacional. A porcentagem de atividade antioxidante $(A A \%)$ corresponde à quantidade de DPPH consumida pelo antioxidante e é obtida através da fórmula abaixo. Também uma curva de regressão linear foi estabelecida, a fim de se calcular a $\mathrm{Cl}_{50}$ (Concentração Inibitória), que significa a quantidade da amostra necessária para reduzir a absorção de DPPH em $50 \%$. AA $\%=$ ABS controle $-\{[(A B S$ amostra - ABS branco) $\times 100]$ / ABS controle\}. ABS controle é a absorbância inicial da solução de DPPH e ABS amostra é a absorbância da mistura reacional (DPPH+amostra). Quanto maior o consumo de DPPH por uma amostra, menor será a sua $\mathrm{Cl}_{50}$, e maior será sua atividade sequestradora.

\section{Ensaio da atividade antimicrobiana in vitro Para os bioensaios da atividade}

antimicrobiana foram empregadas cepas padronizadas originárias da American Type Culture Collection (ATCC), disponíveis no Núcleo de pesquisa da Faculdade de Farmácia-Bioquímica, da Universidade de Cuiabá. No teste da atividade antibacteriana foram utilizadas cepas de Escherichia coli (ATCC 25922), Pseudomonas aeruginosa (ATCC 27853), Enterococcus faecalis (ATCC 29218) e Staphylococcus aureus (ATCC 25923). Para os ensaios da atividade antifúngica foram usadas cepas de Candida albicans (ATCC 90028), Candida glabrata (ATCC 9030) Candida krusei (ATCC 6258) Candida parapsilosis (ATCC 22019) Candida tropicalis (ATCC 760) e Cryptococcus neoformans (ATCC 32045).

Para avaliar a atividade antibacteriana e antifúngica foi utilizada a técnica da microdiluição, de acordo com metodologia descrita na literatura (NCCLS, 2003; NCCLS 2002), com algumas modificações (Mitscher, et al., 1972). A menor concentração do extrato em que não se observou qualquer crescimento de bactérias após a incubação foi registada como a concentração inibitória mínima (CIM). O crescimento microbiano foi detectado pela turbidez dos extratos e confirmado através da adição do reagente, resazurina. Como padrões foram utilizados cloranfenicol para as bactérias e anfotericina $B$ para os fungos. O teste foi realizado em duplicata.

\section{Ensaio toxicológico frente à $A$. salina}

Os extratos e frações das plantas em estudo foram dissolvidos em Dimetilsulfóxido (DMSO), em uma concentração inicial de $20 \mathrm{mg} / 500 \mu \mathrm{L}$ e testados segundo a metodologia proposta por Meyer et al. (1982) e McLaughlin (1998). Ovos de Artemia salina adquiridos comercialmente foram colocados em um recipiente contendo água marinha sintética ( $38 \mathrm{~g} \mathrm{NaCl} / 1000 \mathrm{~mL} \mathrm{H}_{2} \mathrm{O}$ ) e deixados em temperatura ambiente por 48 horas para eclodirem. As amostras foram então diluídas em concentrações diferentes, que variaram de 0,5 a $1000 \mu \mathrm{g} / \mathrm{mL}$ sendo distribuídas em tubos contendo água do mar artificial até completar um volume final de $10 \mathrm{~mL}$. Para efetuar o ensaio, foram colocados, em triplicata, dez exemplares de náuplios nos tubos de ensaio contendo a amostra a ser testada, e novamente deixados em temperatura ambiente por 24 horas. Após este período, o número de microcrustáceos vivos e mortos em cada diluição (concentração) foi contado, com auxílio de um microscópio binocular. $\mathrm{O}$ ensaio foi realizado em triplicata. Como controle positivo foi utilizando sulfato de quinidina e negativo, água marinha. Os resultados foram expressos em $\mu \mathrm{g} / \mathrm{mL}$, como a concentração necessária para matar $50 \%$ das larvas $\left(\mathrm{DL}_{50}\right)$. Para o cálculo final da $\mathrm{DL}_{50}$ e seu respectivo intervalo de confiança de $95 \%$ foi

Rev. Bras. PI. Med., Campinas, v.17, n.4, supl. III, p.1069-1077, 2015. 
utilizado o método estatístico de análise Probitos. As amostras foram consideradas ativas quando $D_{50}$ foi inferior a $1000 \mu \mathrm{g} / \mathrm{mL}$.

\section{RESULTADOS E DISCUSSÃO}

O screening tradicional tem por objetivo a detecção e prospecção preliminar dos diferentes constituintes químicos de plantas, com base na extração destes com solventes apropriados e na aplicação de testes de coloração, ocorrendo algumas vezes a formação de precipitados (Moreira, 1979; Matos, 1997). Através da análise fitoquímica preliminar, foi possível identificar classes de metabólitos secundários de interesse farmacológico presentes nos extratos em estudo, e os resultados encontram-se dispostos na Tabela 2.

Com relação ao teste do DPPH todas as plantas testadas apresentaram significativa atividade sequestradora de radicais livres (Tabela 3 ), uma vez que quanto maior o consumo de DPPH por uma amostra, menor será a sua $\mathrm{IC}_{50}$, e maior será sua atividade sequestradora. Merecem destaque as espécies vegetais $K$. coriaceae $(\mathrm{Ca})\left(\mathrm{IC}_{50}=\right.$ $0,72 \pm 0,51 \mu \mathrm{g} / \mathrm{mL}), K$. coriaceae (Fo) $(1,34 \pm 0,53$ $\boldsymbol{\mu g} / \mathrm{mL}), H$. speciosa (Fo) $(1,03 \pm 0,52 \mu \mathrm{g} / \mathrm{mL}), Q$. grandiflora (Fo) $(1,31 \pm 0,19 \mu \mathrm{g} / \mathrm{mL}$ ) e $P$. rigida (Fo) $(1,39 \pm 0,53 \mu \mathrm{g} / \mathrm{mL})$ quando comparadas ao padrão ácido cafêico $(1,89 \pm 0,52 \mu \mathrm{g} / \mathrm{mL})$. Estes resultados permitem inferir uma capacidade antioxidante dos extratos mencionados, pois antioxidantes são substâncias que retardam ou previnem a oxidação de lipídios ou outras moléculas ao inibem a iniciação ou a propagação da reação de oxidação em cadeia (Al-Mamary et al., 2002; Moreira et al., 2002; Chanwitheesuk et al., 2005; Wu et al., 2005; Lima et al., 2006), além de prevenirem ou repararem danos ocasionados às células pelas espécies reativas de oxigênio (Chanwitheesuk et al., 2005).

Em trabalho realizado por Silva (2008), o conteúdo de fenóis totais e taninos, obtidos da casca do caule de $K$. coriaceae, foi analisado para o extrato bruto, fases e grupos ativos. A fase metanol/hexano demonstrou um forte teor de compostos fenólicos, com $1 \mathrm{mg} / \mathrm{mL}$, sendo $53,56 \%$ de taninos e a fase metanol/água apresentou $0,95 \mathrm{mg} / \mathrm{mL}$ de polifenóis, dos quais $35,96 \%$ são taninos.

A atividade antioxidante, avaliada através do método do DPPH, bem como a determinação dos compostos fenólicos totais do extrato metanólico bruto das folhas e as frações de $P$. rígida, foram quantificados por Rosa et al. (2010). Na determinação do teor de metabólitos secundários, $P$. rígida, os resultados observados demonstraram ser bastante significativo quanto ao conteúdo de flavonoides, com uma concentração superior ao padrão rutina $(440,5$ e 365,5 mg ER/g, respectivamente) (Tabela 3). Há relatos sobre a composição de $P$. rígida acerca da presença de triterpenos derivados de friedelanona (Bolzani et al., 1992), do iridóide loganina (Lopes et al., 2004) e do alcaloide indólico vallesiachotamina (Vencato et al., 2006). Além disso, de acordo com Machado et al. (2010) há estudos que relatam a presença de compostos fenólicos em Palicourea e em outras espécies da família Rubiaceae, o que confirma os resultados aqui apresentados. Para os autores o potencial antioxidante e o teor de compostos fenólicos podem ser úteis quando se correlaciona à atividade anti-inflamatória, a qual está diretamente relacionada ao uso de $P$. rigida.

Convém ressaltar que, com exceção de $L$. paniculata (Fo), que apresentou $I C_{50}$ de $14,40 \pm 0,34$

TABELA 2. Perfil fitoquímico preliminar dos extratos etanólicos de plantas do Cerrado de Mato Grosso.

\begin{tabular}{|c|c|c|c|c|c|c|c|c|}
\hline \multirow[b]{2}{*}{ Plantas } & \multicolumn{3}{|c|}{ Flavonoides } & \multirow[t]{2}{*}{ Alcaloides } & \multirow[t]{2}{*}{ Saponinas } & \multicolumn{2}{|c|}{ Taninos } & \multirow[t]{2}{*}{ Cumarinas } \\
\hline & $\mathrm{NaOH}$ & UV & $\mathrm{HCl}$ & & & MP & ALC & \\
\hline L. paniculata (Fo) & + & + & + & - & + & + & + & - \\
\hline L. paniculata $(\mathrm{Ec})$ & + & + & - & - & - & + & + & - \\
\hline A. colubrina $(\mathrm{Ec})$ & - & - & - & - & & + & + & - \\
\hline C. rubra (Ec) & - & - & - & ++ & + & + & + & - \\
\hline H. speciosa (Fo) & + & + & + & + & + & + & + & - \\
\hline H. speciosa (Ec) & + & - & - & + & + & + & + & - \\
\hline Q. grandiflora (Ec) & - & + & - & + & + & + & + & - \\
\hline Q. grandiflora (Fo) & + & - & - & + & + & + & + & - \\
\hline K. coriaceae $(\mathrm{Ca})$ & + & + & + & - & + & + & + & - \\
\hline K. coriaceae (Fo) & + & + & + & + & + & + & + & - \\
\hline$P$. rigida $(\mathrm{Fo})$ & + & + & + & ++ & - & + & + & - \\
\hline
\end{tabular}

$\mathrm{NaOH}$ : Teste com hidróxido de sódio; UV: Teste ultravioleta; HCl: Teste com ácido clorídrico; MP: Teste com metais pesados; ALC: Teste com alcaloides.

Rev. Bras. PI. Med., Campinas, v.17, n.4, supl. III, p.1069-1077, 2015. 
TABELA 3. Quantificação de metabólitos secundários: fenóis totais, flavonoides e cumarinas e atividade sequestradora do radical DPPH dos extratos etanólicos de plantas do Cerrado de Mato Grosso.

\begin{tabular}{lllll}
\hline Plantas & mg EAT/g & mg ER/g & mg EC/g & IC50 $(\boldsymbol{\mu g}) \mathbf{\pm} \mathbf{D P}$ \\
\hline L. paniculata (Ec) & 2,4 & 120,5 & 15,9 & $6,13 \pm 0,26$ \\
L. paniculata (Fo) & 63,6 & 295,5 & 57,3 & $14,40 \pm 0,34$ \\
A. colubrina (Ec) & 75,6 & 5,5 & 13,0 & $6,20 \pm 0,23$ \\
C. rubra (Ec) & 97,6 & 15,5 & 28,7 & $9,31 \pm 0,26$ \\
H. speciosa (Fo) & 91,6 & 280,5 & 33,0 & $1,03 \pm 0,52$ \\
H. speciosa (Ec) & 165,6 & 40,5 & 14,4 & $4,49 \pm 0,56$ \\
Q. grandiflora (Ec) & 53,6 & 75,5 & 48,7 & $2,67 \pm 0,31$ \\
Q. grandiflora (Fo) & 117,6 & 260,5 & 50,1 & $1,31 \pm 0,19$ \\
K. coriaceae (Ca) & 143,6 & 250,5 & 58,7 & $0,72 \pm 0,53$ \\
K. coriaceae (Fo) & 197,6 & 235,5 & 55,9 & $1,34 \pm 0,51$ \\
P. rigida (Fo) & 179,6 & 440,5 & 75,9 & $1,39 \pm 0,53$ \\
Padrões & 885,6 & 365,5 & 137,3 & $1,89 \pm 0,52$ \\
\hline
\end{tabular}

$\mathrm{mg} E A T / \mathrm{g}$ = miligrama equivalente de ácido tânico por grama da amostra; $\mathrm{mg}$ ER/g = miligrama equivalente de rutina por grama de amostra; $\mathrm{mg} \mathrm{EC/g}=$ miligrama equivalente de cumarina por grama de amostra.

Os valores foram determinados por regressão linear e expressos como médias \pm DP (desvio padrão) de experimentos em triplicata.

$\mathrm{DPPH}=$ 2,2-difenil-1-picrilhidrazina; Padrão: Ácido cafêico; $\mathrm{IC}_{50}=$ os valores foram determinados por regressão linear e expressos em média \pm DP (desvio padrão) dos experimentos em triplicata.

$\boldsymbol{\mu g} / \mathrm{mL}$ e teor de flavonoides de $295,5 \mathrm{mg} / \mathrm{g}$, todas as espécies que tiverem significativa atividade no teste do DPPH, também apresentaram teor de flavonoides semelhante ao padrão, ou seja, $H$. speciosa (Fo) (280,5 mg/g), Q. grandiflora (Fo) $(260,5 \mathrm{mg} / \mathrm{g}), \mathrm{K}$. coriaceae (Ca) $(250,5 \mathrm{mg} / \mathrm{g}), K$. coriaceae (Fo) (235,5 mg/g).

As substâncias com núcleo fenólico, como os flavonoides e ácidos fenólicos, apresentam destaque especial como antioxidantes, por atuarem como eficientes sequestradores de espécies reativas de oxigênio (EROs), além de reduzirem e quelarem íons férrico que catalisam a peroxidação lipídica (Al-Mamary et al., 2002; Nahar \& Sarker, 2005; Delazar et al., 2006).

Os extratos etanólicos brutos foram avaliados frente às cepas fúngicas e bacterianas descritas neste trabalho e os resultados são apresentados na Tabela 4. Com base nos valores da concentração inibitória mínima (CIM) obtidos verificou-se que os extratos de C. rubra e $Q$. grandiflora foram os mais ativos contra as cepas fúngicas de $C$. neoformans (CIM 3,91 $\mu \mathrm{g} / \mathrm{mL}$ ), $C$. krusei (CIM 15,63 $\mu \mathrm{g} / \mathrm{mL}$ ), C. parapsilosis (CIM 31,25 $\mu \mathrm{g} / \mathrm{mL}$ ) e C. albicans (CIM 62,5 $\mu \mathrm{g} / \mathrm{mL}$ ), ambos com os mesmos resultados para estes microrganismos. Cepas de C. glabrata e C. tropicalis se mostraram resistentes frente a todos os extratos ensaiados.

Em relação às cepas bacterianas a mais sensível foi $S$. aureus com CIM de $250 \mu \mathrm{g} / \mathrm{mL}$ para todos os extratos testados. Luhea paniculata e Q. grandiflora foram as espécies vegetais mais ativas contra E. coli (CIM 500 e $250 \mu \mathrm{g} / \mathrm{mL}$, respectivamente) e E. faecalis (CIM 250 e $500 \mu \mathrm{g} /$ $\mathrm{mL}$, respectivamente).

O extrato etanólico obtido da casca de $Q$. grandiflora foi investigado por sua capacidade de prevenir e curar lesões na mucosa gástrica (HirumaLima et al., 2006) e o extrato metanólico apresentou ação antibacteriana sobre $S$. aureus, Bacillus cereus e Pseudomonas aeruginosa (Alves et al., 2000). O extrato etanólico das folhas apresentou efeitos antioxidantes (Souza et al., 2007), analgésicos, depressores do sistema nervoso central, com potencial anticonvulsivante (Gaspi et al., 2006) e atividade antibacteriana contra Staphylococcus epidermidis (Ayres et al., 2008) .

Os extratos das espécies vegetais Hancornia speciosa, Palicourea rígida e Luhea paniculata (folhas) não se demonstraram ativos frente as cepas bacterianas testadas. Porém, os extratos brutos de Kielmeyera coriaceae (folhas e entrecasca) apresentaram atividade contra $S$. aureus (CIM $500 \mu \mathrm{g} / \mathrm{mL}$ ).

Em ensaio realizado por Cortez et al. (2002) com aucuparin, um composto isolado da fase diclorometânica obtido das folhas de K. coriaceae, demonstrou a atividade contra $S$. aureus com um valor de CIM de $12,5 \mu \mathrm{g} / \mathrm{ml}$. Em outro estudo, o extrato hexânico de casca da raiz de K. coriacea foi selecionado para estudos biomonitorados devido a atividade significativa contra $S$. aureus (zona de inibição de $14 \mathrm{~mm}$ ) (Taveira, 2007), justificando os resultados deste trabalho.

Em estudo realizado por Santos et al. (2007), com o látex obtido de $H$. speciosa foi

Rev. Bras. PI. Med., Campinas, v.17, n.4, supl. III, p.1069-1077, 2015. 
TABELA 4. Concentração Inibitória Mínima $(\mu \mathrm{g} / \mathrm{mL})$ dos extratos etanólicos de plantas do Cerrado de Mato Grosso.

\begin{tabular}{lllllllllll}
\hline & \multicolumn{1}{c}{ Cepas fúngicas } & \multicolumn{1}{c}{ Cepas bacterianas } \\
\cline { 2 - 11 } \multicolumn{1}{c}{ Plantas } & Ca & Cg & Ck & Cp & Ct & Cn & Ec & Pa & Ef & Sa \\
\hline A. colubrina (Ec) & 500 & a & 250 & 1000 & a & 62,5 & a & 1000 & A & 250 \\
C. rubra (Ec) & 62,5 & a & 15,63 & 31,25 & a & 3,91 & 1000 & 1000 & 1000 & 250 \\
L. paniculata (Ec) & 500 & a & 250 & a & a & 1000 & 500 & a & 250 & 250 \\
L. paniculata (Fo) & NT & NT & NT & NT & NT & NT & a & a & a & a \\
Q. grandiflora (Ec) & 62,5 & 1000 & 15,63 & 31,25 & a & 3,91 & 250 & a & 500 & 250 \\
Q. grandiflora (Fo) & NT & NT & NT & NT & NT & NT & a & a & a & a \\
H. speciosa (Ec) & NT & NT & NT & NT & NT & NT & a & a & a & a \\
H. speciosa (Fo) & NT & NT & NT & NT & NT & NT & a & a & a & a \\
K. coriaceae (Ca) & NT & NT & NT & NT & NT & NT & a & a & a & 500 \\
K. coriaceae (Fo) & NT & NT & NT & NT & NT & NT & a & a & a & 500 \\
P. rigida (Fo) & NT & NT & NT & NT & NT & NT & a & a & a & a \\
Anfotericina B & 2 & 8 & 8 & 4 & 8 & 2 & - & - & - & - \\
Cloranfenicol & - & - & - & - & & & $<0,3$ & 8 & 0,5 & 0,5 \\
\hline
\end{tabular}

Ca: C. albicans; Cg: C. glabrata; Ck: C. krusei; Ct: C. tropicalis; Cn: C. neoformans; Ec: E. coli; Pa: P. aeruginosa; Ef: E. faecalis; Sa: S. aureus; a: CIM >1000; NT: não testado

observado que esta espécie não apresentou atividade antimicrobiana para os microrganismos Candida albicans, Mycobacterium tuberculosis, Staphylococcus aureus, Neisseria meningitidis, Streptococcus spp., Streptococcus pneumoniae, Cryptococcus neoformans var. neoformans e Cryptococcus neoformans var. gatti, segundo o método de difusão em disco, o que confirma, em partes, os resultados apresentados, uma vez que as técnicas são diferentes e apenas $S$. aureus foi testado.

Para a espécie $P$. rígida, há na literatura relatos sobre as atividades citotóxica (Silva et al., 2005) e antimicrobiana do seu extrato bruto (Silva et al., 2006), havendo desta forma, a necessidade de se utilizar outras técnicas para confronto dos resultados.

Em um trabalho realizado por Gonçalves et al. (2005), extrato da casca de Anadenanthera colubrina não mostrou propriedades antibacterianas contra isolados clínicos.

O ensaio da letalidade de organismos simples é baseado na correlação observada entre a toxidez sobre o microcrustáceo e a citotoxicidade sobre células cancerosas do tipo P-388, sendo considerado um bioensaio preliminar no estudo de extratos brutos e substâncias puras vegetais com potencial atividade anticâncer, além de ser um método rápido, seguro e acessível (Meyer, 1982; McLaughlin, 1998). Desta forma, o ensaio permite a avaliação da toxicidade geral e, portanto, é considerado essencial como bioensaio preliminar no estudo de compostos com potencial atividade biológica. Os extratos etanólicos brutos de todas as espécies vegetais testadas não apresentaram atividade citotóxica sobre as larvas de $A$. salina. As amostras foram consideradas inativas, pois apresentaram $\mathrm{DL}_{50}$ superior a $1000 \mu \mathrm{g} / \mathrm{mL}$, enquanto que o padrão sulfato de quinidina apresentou $\mathrm{DL}_{50}=$ $337,3 \mu \mathrm{g} / \mathrm{mL}$. Estes dados sugerem a ausência de componentes citotóxicos nestas espécies.

\section{CONCLUSÃO}

No teste da atividade sequestradora de radicais livres o caule e as folhas de $K$. coriaceae, as folhas de $H$. speciosa e a entrecasca de $Q$. grandiflora foram os mais potentes. Estes resultados sugerem a presença de compostos que contribuem particularmente e mais efetivamente para a ação sequestradora de radicais livres, no extrato destas três espécies. No teste da atividade antifúngica, as plantas C. rubra e Q. grandiflora foram as mais ativas contra as cepas fúngicas e no ensaio da atividade antibacteriana $L$. paniculata e Q. grandiflora foram as que apresentaram resultados mais significativos. Certamente os resultados obtidos com os extratos de algumas destas plantas corroboram os seus usos como antimicrobianos em terapêutica popular. Entretanto, é possível também constatar que alguns microrganismos são resistentes a todos estes extratos, o que torna inócua a utilização destas plantas frente a uma infecção por estes microrganismos resistentes. Considerando que 
substâncias naturais podem ser responsáveis pelo efeito de proteção contra os riscos de muitos processos patológicos, os resultados descritos neste trabalho, estimulam a continuidade dos estudos para avaliar a ação antioxidante de substâncias isoladas das espécies. Os dados sugerem a ausência de componentes citotóxicos nestas espécies. Contudo, para avaliação da toxicidade de plantas outros ensaios são propostos pela literatura e deve ser realizados.

\section{AGRADECIMENTO}

Fundação de Amparo à Pesquisa do Estado de Mato Grosso (FAPEMAT) e Universidade de Cuiabá (UNIC).

\section{REFERÊNCIAS}

AL-MAMARY, M.; et al., Antioxidant activities and total phenolics of different types of Honey. Nutrition Research, v. 22, p.1041-1047, 2002.

ALVES, T. M. A.; et al.,.; Biological screening of brazilian medicinal plants. Memórias do Instituto Oswaldo Cruz, v. 95, p. 367-373, 2000.

AMORIM, E.L.C.; et al., simple and accurate procedure for determination of tannin and flavonoid levels and some aplications in ethnobotany and ethnopharmacology. Functional Ecology, v.2, p. 88-94, 2008.

ANDRADE, D.; et al., Ocorrência de bactérias multirresistentes em um Centro de Terapia Intensiva de Hospital Brasileiro de Emergências. Revista Brasileira de Terapia Intensiva, p.18, p.27-33, 2006.

ANTAS E SILVA, D.A.; et al., Constituintes químicos e atividade antioxidante de Sida galheirensis Ulbr. (Malvaceae). Química Nova, v.29, p.1250-1254, 2006.

ANTUNES, R.M.P.; et al., Atividade antimicrobiana "in vitro" e determinação da concentração inibitória mínima (CIM) de fitoconstituintes e produtos sintéticos sobre bactérias e fungos leveduriformes. Revista Brasileira de Farmacognosia, v.16, p.517-524, 2006.

ARNAO, M.B.; et al., A method to measure antioxidant activity in organic media: application to lipophilic vitamins. Redox Report, v.5, p.365:370, 2000.

AYRES, M.C.C.; et al., Atividade antibacteriana de plantas úteis e constituintes químicos da raiz de Copernicia prunifera. Revista Brasileira de Farmacognosia, v. 18, p. 90-97, 2008.

BOLZANI, V.S.; et al., Triterpenes of Palicourea rígida H.B.K. Revista Latinoamericana de Quimica, v. 23, p. 20:21, 1992.

CECHINEL FILHO, V.; YUNES, R.A. Estratégias para a obtenção de compostos farmacologicamente ativos a partir de plantas medicinais. Conceitos sobre modificação estrutural para otimização da atividade. Química Nova, v.21, p.99-105, 1998.

CHANWITHEESUK, A.; et al., Screening of antioxidant activity and antioxidant compounds of some edible plants of Thailand. Food Chemistry, v.92, p. 491-497, 2005.
CORTEZ, D.A.G.; et al., Antibacterial Activity of a Biphenyl and Xanthones from Kielmeyera coriacea. Pharmaceutical Biology, v.40, p.485-489, 2002.

DELAZAR, A.; et al., Chrozophorin: a new acylated flavone glucoside from Chrozophora tinctoria (Euphorbiaceae). Revista Brasileira de Farmacognosia, v. 16, p.286290, 2006.

GASPI, F.O.G.; et al., Pharmacological activities investigation of crude extracts and fractions from Qualea grandiflora Mart. Journal of Ethnopharmacology, v.107, p.19-24, 2006.

GONÇALVES; A.L; et al., Estudo comparativo da atividade antimicrobiana de extratos de algumas árvores nativas. Arquivo do Instituto de Biologia, v.72, n.3, p.353-358, 2005.

GUARIN NETO, G.; MORAIS, R.G. Recursos medicinais de espécies do cerrado de Mato Grosso: um estudo bibliográfico. Acta Botânica Brasileira, v.17, p.561584, 2003.

HIRUMA-LIMA, C.Aet al., Brazilian “Cerrado" medicinal plant presents an important antiulcer activity. Journal of Ethnopharmacology, v.104, p.207-214. 2006.

KINGHORN, A.D. Pharmacognosy in the 21st century. Journal of Pharmacy and Pharmaceutical Sciences, v.53, p.135-148, 2001.

LIMA, A.R.; et al., Avaliação in vitro da atividade antioxidante do extrato hidroalcoólico de folhas de bardana. Revista Brasileira de Farmacognosia, v.16, p.531-536, 2006.

LOPES, S; et al., Taxonomic significance of alkaloids and iridoid glucosides in the tribe Psychotrieae (Rubiaceae). Biochemical Systematics and Ecology, v.32, p.11871195, 2004.

MACEDO, M.I.; FERREIRA, A.R. Plantas hipoglicemiantes utilizadas por comunidades tradicionais na Bacia do Alto Paraguai e Vale do Guaporé, Mato Grosso- Brasil. Revista Brasileira de Farmacognosia, v.14, p.45-47, 2004.

MACHADO, A.D.O.; et al., Breeding biology and distyly in Palicourea rigida H. B. \& K. (Rubiaceae) in the Cerrados of Central Brazil. Acta Botanica Brasileira, v.24 p.686696, 2010.

MATOS, F.J. Introdução à fitoquímica experimental. 2.ed. Fortaleza: Edições UFC; 1997. 141p.

MCLAUGHLIN, J.L. The use of biological assays to evaluate botanicals. Drug Information Journal, v.32, p.513-524, 1998.

MEYER, B.N. Brine shrimp: A convenient general bioassay for active plant constituents. Planta Medica, v.45, p.3134, 1982.

MITSCHER, L.A.; et al., Antimicrobial agents from higher plants.1. Introduction, rationale, and methodology. Lloyd, v.35, p.157-161, 1972.

MOREIRA, D.L.; et al., Substâncias fenólicas com atividade antioxidante de Pseudopiptadenia contorta (Leguminosae-Mimosoideae). Revista Brasileira de Farmacognosia, v.12, p.124-125, 2002.

MOREIRA, E.A. Marcha sistemática de análise em fitoquímica. Tribuna Farmacêutica, v.47, p.1-19, 1979.

NAHAR, L.; SARKER, S.D. Chenoalbuside: an antioxidant phenolic glycoside from the seeds of Chenopodium album L. (Chenopodiaceae). Revista Brasileira de Farmacognosia, v.15, p.279-282, 2005. 
NAPOLITANO, D.R.; et al.,Down-modulation of nitric oxide production in murine macrophages treated with crude plant extracts from the Brazilian Cerrado. Journal of Ethnopharmacology, v.99, p.37-41, 2005.

NCCLS - National Committee for Clinical Laboratory Standarts - Método de referência para testes de sensibilidade a agentes antimicrobianos por diluição para bactérias de crescimento aeróbio: Norma Aprovada. 6 ed. Norma M7-A6. 2003. Disponível em: <www.anvisa.gov>Acesso em: 26 nov de 2014.

NCCLS - National Committee for Clinical Laboratory Standarts. Método de referência para testes de diluição em caldo para a determinação da sensibilidade a terapia antifúngica das leveduras: Norma Aprovada. 2ed. Norma M27-A2. 2002. Disponível em: <www.anvisa.gov> Acesso em: 26 nov 2012

ROSA, E.A.; et al.,. Flavonoides e atividade antioxidante em Palicourea rigida Kunth, Rubiaceae. Revista Brasileira de Farmacognosia, v.20, p.484-488, 2010.

SANTOS, P.O.; et al., Investigação da atividade antimicrobiana do látex da mangabeira (Hancornia speciosa GOMES). Revista Brasileira de Plantas Medicinais, v.9, p.108-111, 2007.

SAWYER,D.; et al., O papel da sociedade no estabelecimento de políticas públicas para as savanas. Savanas: Desafios e estratégias para o equilíbrio entre sociedade, agronegócio e recursos naturais. Planaltina: EMBRAPA Cerrados, p. 1153:1180, 2008. Disponível em: <http://portais.ufg. br/up/160/o/savanas_20publicado.pdf>. Acesso em 10 dez 2015.

SILVA, C.G.; et al., Evaluation of antioxidant activity of Brazilian plants. Pharmacological Research, v. 52, p. 229-233, 2005.

SILVA, E.M. Ação inibitória de extratos de plantas do cerrado sobre $\alpha$-amilases com ênfase em Kielmeyera coriacea. 2008. 141f. Dissertação (Mestrado em Ciências da Saúde). Universidade de Brasília, Brasília.

SIMÕES, C.M.O.; SCHENKEL, E.P.; GOSMANN, G.; MELLO, J.C.P.; MENTZ, L.A.; PETROVICK, P.R. Farmacognosia, da planta ao medicamento. 5 ed. Florianópolis:UFRGS: 2004. 821p.

SOBRINHO, T.J.S.P.; et al., Phenolic content and antioxidant capacity of our Cnidoscolus species (Euphorbiaceae) used as ethnopharmacologicals in Caatinga. African Journal of Pharmacy and Pharmacology, v.5 p.2310-2316, 2011.

SOUZA, C.M.M.; et al., Fenóis totais e atividade antioxidante de cinco plantas medicinais. Química Nova, v. 30, p. 351-355, 2007.

TAVEIRA, C.C.; Ação antimicrobiana de extratos de plantas do Cerrado e isolamento de substância ativa de Kielmeyera coriacea. 2007. 62p. Dissertação (Mestrado em Ciências Médicas) - Faculdade de Medicina, Universidade de Brasília, Brasília.

VENCATO I.; et al., Vallesiachotamine. Acta Crystallogrphy, v. 62, p. 429:430, 2006.

WU, J.H.; et al., Phenolic antioxidants from the heartwood of Acacia confusa. Journal of Agricultural and Food Chemistry, v. 53, p.5917-5921, 2005. 